\title{
A Comparative Study on Procedure and State of the Art of Conventional Maximum Power Point Tracking Techniques for Photovoltaic System
}

\author{
Mohammadmehdi Seyedmahmoudian ${ }^{1 *}$, Arash Mohamadi ${ }^{2}$, Swarna Kumary ${ }^{1}$, Aman Maung \\ Than $0^{1}{ }^{1}$, Alex Stojcevski ${ }^{1}$ \\ ${ }^{1}$ School of Engineering, Faculty of Science, Engineering \& Built Environment, Deakin University, Victoria, \\ Australia. \\ ${ }^{2}$ Department of Electrical Engineering, Faculty of Engineering, University of Malaya, Kuala Lumpur, \\ Malaysia. \\ * Corresponding author. Tel.: +61404515649; email: mseyedma@deakin.edu.au \\ Manuscript submitted July 25, 2014; accepted September 28, 2014. \\ doi: 10.17706/ijcee.2014.v6.859
}

\begin{abstract}
Due to the increasing world energy demand, renewable energy systems have been significantly applied in the power generation sector. Among the renewable energy options, photovoltaic system is one of the most popular resources which has been experiencing a huge attention during recent decades. The remarkable advantages, such as static and movement free characteristics, low maintenance costs, and longevity are the primary factors for the popularity of solar generation in the late years. Nevertheless, the low PV conversion efficiency in one side and high PV material cost in the other side have made PV generation comparably expensive system. Consequently, a capable maximum power point tracking (MPPT) is all important to elicit the maximum energy from the production of PV systems. Different researches have been conducted to design a fast, simple and robust MPPT technique under uniform conditions. However, due to the series and parallel connection of PV modules and according to the use of bypass diodes, in the structure of PV modules, a conventional techniques are unable to track a true MPP. Recently, several studies have been undertaken to modify these conventional methods and enable them to track the global MPP under rapidly changing environments and partial shading (PS) conditions. This report concentrates on the state of the art of these methods and their evolution to apply under PS conditions. The recent developments and modifications are analyzed through a comparison based on design complexity, cost, speed and the ability to track the MPP under rapid environmental variations and PS conditions.
\end{abstract}

Key words: Energy efficiency, maximum power point tracking, partial shading condition, photovoltaic system.

\section{Introduction}

Due to the increasing rates of energy demand, renewable energy resources are playing important roles in current energy generation developments. Among different types of renewable energy resources, Photovoltaic (PV) system is one of the most popular resources which has received extra attention during recent decades The output Power - Voltage characteristic of a photovoltaic system is affected by environmental factors such as solar irradiance and temperature levels. Finding the maximum extractable power at the nonlinear output characteristic of the PV system is one of the influential factors affecting the 
efficiency and overall cost of the control unit in a photovoltaic system[1]-[3].

Different studies have been conducted to introduce the efficient maximum power point tracking (MPPT) methods. Perturbation and observation (P\&O), Hill climbing (HC) and Incremental conductance (InCond.) are the most common methods which have shown very fast and efficient response when the solar irradiance cover all PV array, uniformly [4]-[13]. However, the conventional version of these methods is inefficient when mismatching conditions occur [14]-[16]. Several studies have been undertaken to modify the performance of these conventional methods and upgrade them to be applied on PV system under partial shading (PS) conditions. This paper presents the basics and state of the art of the conventional methods by analysing the results of reliable references in the literature.

Three most common conventional methods have been covered in this study and are evaluated by following steps: in the first step the modelling and characteristics of the photovoltaic system is briefly presented. In the second step, basics, procedures and developments of each method are described. In the third step, the fundamental criteria for comparing the conventional methods and their developments are defined. Finally, in the fourth step, the conclusion of the study as well as future works are presented.

\section{Photovoltaic System}

\subsection{Characteristic of PV System}

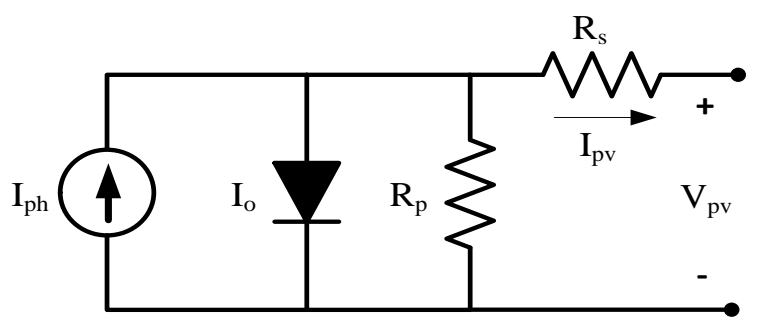

Fig. 1. General circuitry diagram of PV cell.

Recent researches have accurately and comprehensively covered the different methods of modelling and simulation of photovoltaic systems [17], [18]. The typical circuitry diagram of photovoltaic cell is shown in Fig. 1. In general, the output characteristics of the module can be calculated as presented in (1) while the module is operating at the temperature of $T$ and irradiance of $G$.

$$
P\left(I_{p v}, V_{p v}\right)=\left(I_{p h}-I_{o}\left[\exp \left(\frac{q\left(V_{p v}+I_{p v} R_{s}\right)}{N_{s} A K T_{k}}\right)-1\right]-\frac{\left(V_{p v}+I_{p v} R_{s} N_{s}\right)}{R_{p} N_{s}}\right) \times\left(V_{p v}\right)
$$

where, Iph and Io are the solar-generated current and the diode saturation current respectively. $q$ Refers to the Electron Charge constant, $K$ the Boltzmann constant, and $A$ the Diode ideality factor. The number of cells connected to the series circuit is indicated by $N s$, while the numbers of those in parallel are symbolized by $N p$. Fig. 2 represents the I-V and P-V characteristics of the BP SX 150s PV module for different insolation levels. The manufacturing specification of state module can be obtained from Table 1.

Table 1. Photovoltaic Module Specification

\begin{tabular}{ll}
\hline \hline Channels & Group 1 \\
\hline Open circuit voltage & $43.5 \mathrm{~V}$ \\
Short circuit current & $4.75 \mathrm{~A}$ \\
Maximum power voltage & $34.5 \mathrm{~V}$ \\
Maximum power current & $4.35 \mathrm{~A}$ \\
Maximum power & $150 \mathrm{~W}$ \\
\hline \hline
\end{tabular}



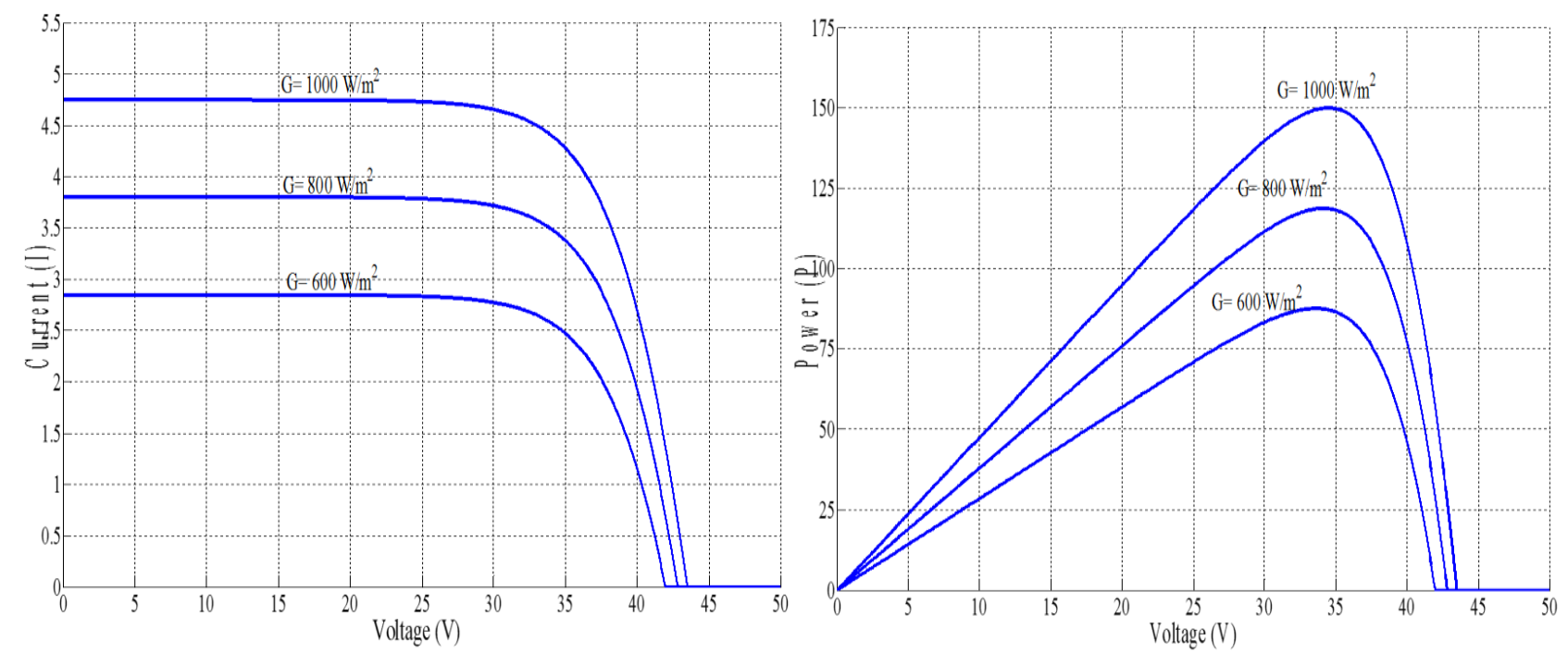

Fig. 2. Behavior of PV system in different irradiance levels.

\subsection{Effects of Partial PS Conditions}

Mismatching conditions are unavoidable circumstances in which some percentage of PV module malfunctions due to different causes such as ageing, shading or disconnection. The most usual and inevitable type of mismatching condition is partial shading. In any outdoor environment, the whole or some components of the PV system might be shadowed by trees, passing clouds, high building, etc., which result in non-uniform insolation conditions. During partial shading, a fraction of the PV cells, which receive uniform radiance still operate at the optimum efficiency. Since current flow through every cell in a series configuration is naturally constant, the shaded cells need to operate with a reverse bias voltage to supply the same current as the illumined cells. Nevertheless; the resulting reverse power polarity leads to power consumption and a decrease in the maximum output power of the partially shaded PV module. Exposing the shaded cells to an excessive reverse bias voltage could also cause "hot spots" to appear in them, and creating an open circuit in the entire PV module. This is often resolved with the inclusion of a bypass diode to a specific number of cells in the series circuit. The presence of bypass diode for mitigating the negative effects of PS conditions will create a multiple peaks characteristic at the output of the PV array [18].

\section{Conventional MPPT Methods}

\subsection{Perturbation and Observation (P\&0) Method}

$\mathrm{P} \& 0$ is one of the most common conventional methods used for MPP tracking techniques in several researches [19]-[21]. This iterative based method measures the output characteristic of the PV systems and changes the operating duty cycle of the DC/DC converter. First, the operating duty cycle, and consequently operation voltage, is perturbed by a slight change (C). Then the consequent power at the output of the PV is calculated to obtain the power changes $(\Delta \mathrm{P})$ between the current and previous operating point. According to the statement presented in (2) if the variation of the power, as a result of this voltage perturbation, is positive, then the perturbation of the voltage follows the same direction. If the power variation is negative, then the operating voltage should be moved in the opposite direction [22]. The procedure of basic P\&O technique is shown in Fig. 3.

$$
\left\{\begin{array}{lll}
V p v+\Delta V & \text { if } & \Delta P>0 \\
V p v-\Delta V & \text { if } & \Delta P<0
\end{array}\right.
$$


The main disadvantage of this method appears while there is a sudden change in the solar irradiance levels. Under this condition, the next operating point follows the opposite direction toward the actual MPP. As long as these sudden changes continue, the operating point moving away from the actual MPP [23].

The improved version of $\mathrm{P} \& \mathrm{O}$ technique has been presented in [24]-[26]. The performance of the algorithm under sudden environmental changes has been modified in [24], [25], [27] and the steady state osculation has been improved in [26]. An improved P\&O method has been proposed in [28], where the $d$ axis grid current component reflecting the power grid side and the signal error of a proportional-integral (PI) outer voltage regulator is designed to reflect the change in power caused by the irradiation variation. In [24] the author used an optimized P\&O MPPT, in which the algorithm parameters are customized to the dynamic behaviour of the specific converter adopted. The behavior of the proposed methods has been improved in terms of reducing the oscillation around MPP as well as increasing the accuracy under rapid environmental changes. However, the ability of the method for tracking the MPP under PS conditions is not proved.

The authors in [29] improved the performance of normal P\&O technique under PS conditions, by tuning the duty cycle of connected DC/DC convertor to find all appeared local and global MPPs between lowest and highest duty cycles. The presented results are promising under both normal and PS conditions. However, the required time for identifying all MPPs reduces the tracking speed of the technique.

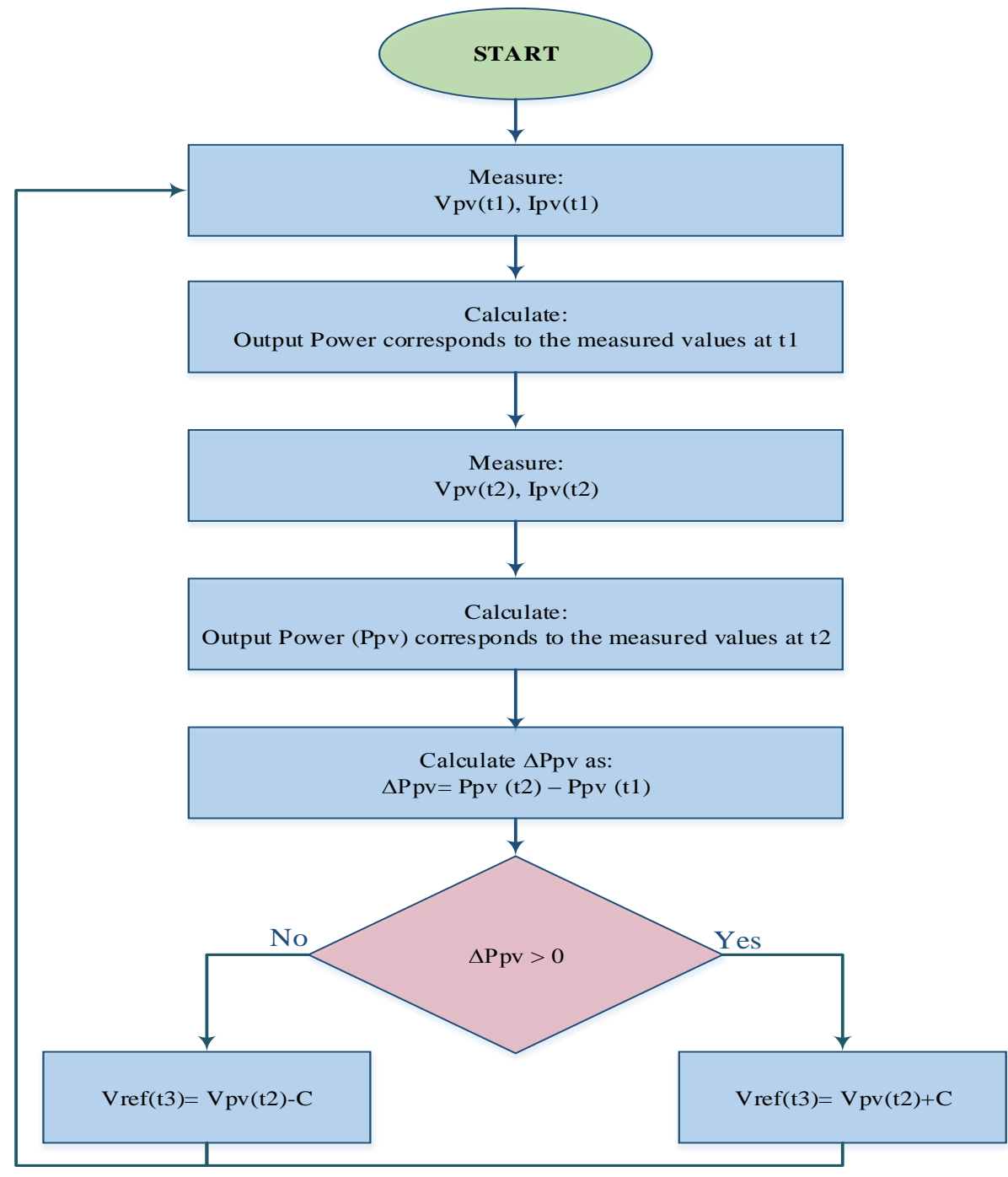

Fig. 3. Flowchart of $\mathrm{P} \& O$ algorithm. 


\subsection{Hill Climbing Method (HC)}

Hill climbing method (HC) is another common conventional MPPT technique which has been regularly used in the literature [6], [30]-[35]. In a similar procedure to P\&O technique, the voltage is regulated to follow the maximum output power. The only difference is that instead of perturbing the operating voltage, the operating duty cycle is perturbed in HC method.

The duty cycle is simultaneously perturbed with a step size of $Q$ until the maximum power is found. The difference between the current output power and the previously measured value is continuously calculated. If the current power is higher than previous one, the duty cycle will be perturbed in the same direction, otherwise, the slope of the duty cycle movement will be inverse. The conditional statement to define the direction of the operating point and duty cycle perturbation is stated in (3).

$$
\begin{cases}D(t)=D(t-1)+Q & P(t)<P(t-1) \\ D(t)=D(t-1)-Q & P(t)>P(t-1)\end{cases}
$$

The procedure and steps of $\mathrm{HC}$ algorithm are presented in Fig. 4. As shown in this figure, the algorithm continues operating until oscillating around MPP. In case of zero difference between current and previous output power values, the output current and voltage will be measured again.

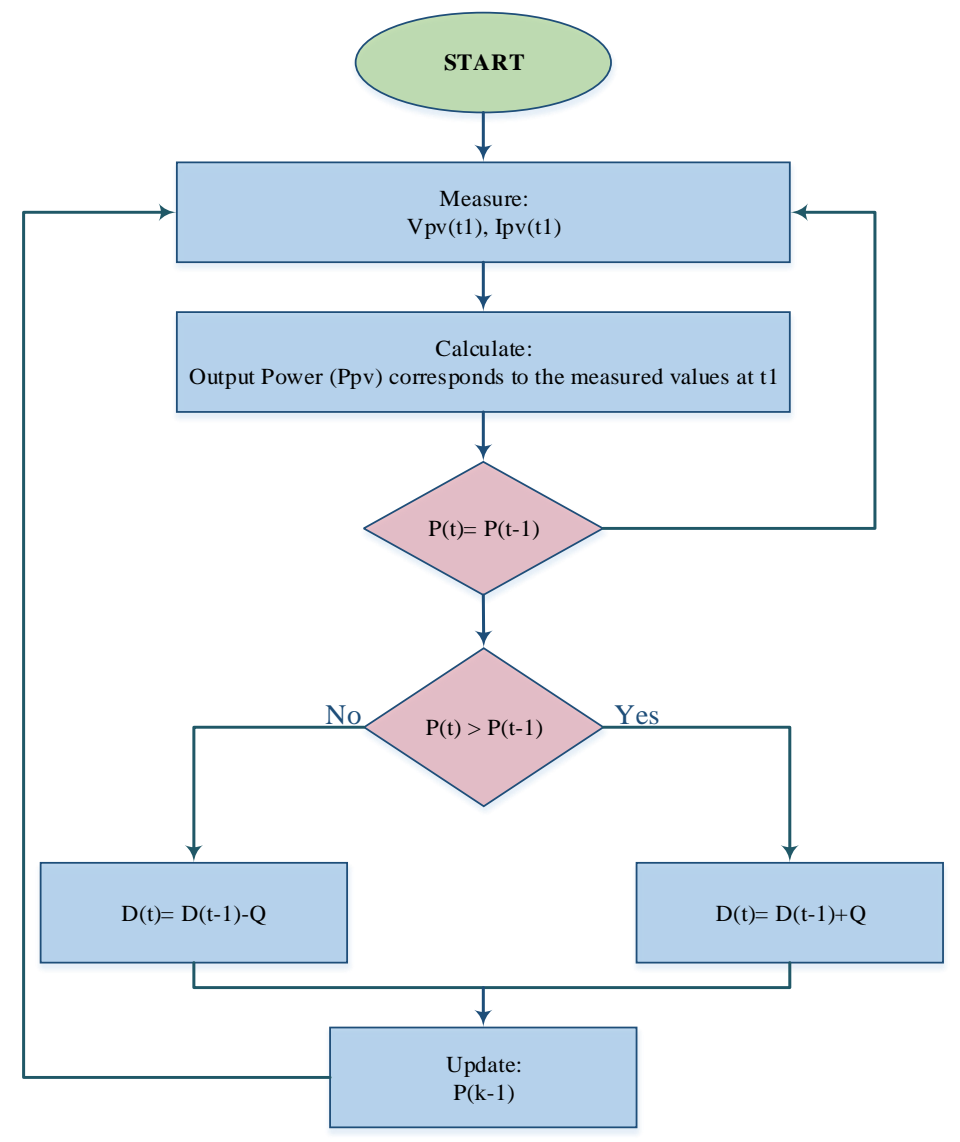

Fig. 4. Flowchart of HC algorithm.

The main advantage of Hill climbing method is its simplicity in design and implementation. However, alike $\mathrm{P} \& \mathrm{O}$ method, $\mathrm{HC}$ technique is vulnerable in tracking under rapidly changing environmental conditions. In addition, same as other conventional method, it is not able to track the actual MPP under mismatching 
conditions when multiple peaks appear in the output power-voltage characteristic.

Due to the significance of above mentioned drawbacks, many researches have been working on the modification of the normal HC method. For instance, in [16], the author employed an adaptive HC based MPPT method to track the MPP under rapidly shading conditions. In this method an automatic parameter tuning approach is used for controlling the switching mode and tuning the system under sudden changing conditions. However, the proposed technique is only capable of finding MPP under uniform insolation levels.

In another study presented in [33], a duty cycle sweep method has been proposed to enforce HC capability under PS conditions. In this method, the algorithm first defines the initial value of duty cycle by using the following equation:

$$
D=\left(1-\sqrt{\frac{R m}{R l}}\right)
$$

In which $R m$ is a proportion of $V o c / I s c$ value and $R l$ is an estimated value. Then, it uses a large-size scan method to check around $90 \%$ of the search space for finding the MPP region. Finally, it employs the improved HC method to track the accurate value of MPP. In the improved HC method the value of step size is reduced to half for avoiding oscillation around MPP. The method shows satisfactory performance under both normal and PS conditions. However, it is considered as system dependent technique, as it needs to scan around $\% 90$ of the output PV characteristic.

\subsection{Incremental Conductance (InCond) Method}

InCond is another common conventional method which has been frequently used in the literature [11], [36]-[42]. This method is generally based on the derivation of output put PV relationship. Therefore, the maximum power point would be achieved when the derivation is zero as presented in (4).

$$
\frac{d P p v}{d V p v}=0 \Rightarrow I p v \frac{d V p v}{d V p v}+V p v \frac{d I p v}{d V p v}=0 \Rightarrow \frac{d I p v}{d V p v}=-\frac{I p v}{V p v}
$$

By assuming $d V p v \approx \Delta V p v$ and $d I p v \approx \Delta I p v$, the following equation defines the location of operating point in respect to the actual MPP:

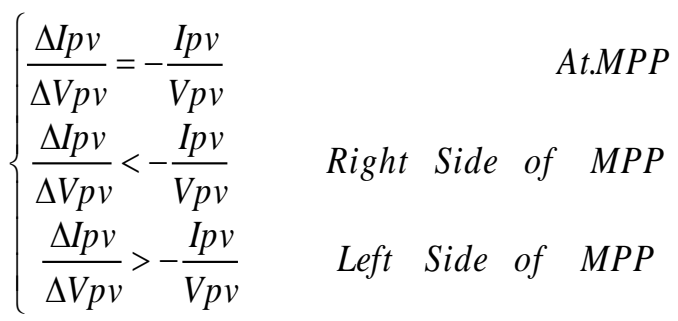

The procedure and different steps of the InCond MPPT technique is described in the flowchart shown in Fig. 5. The flowchart shows that the MPP is tracked by simultaneous comparison of InCond $(\Delta V p v / \Delta I p v)$ and instantaneous conductance ( $\mathrm{Vpv} / \mathrm{Ipv}$ ) [43].

Based on the location of the operating point in the output characteristic, the controller moves the operating point with a step size of $\mathrm{C}$ to approach MPP.

Tracking speed of the controller is largely dependent on the value of the step size. A large step size value 
helps to track the MPP faster, however, it results the oscillation around the MPP. This problem has been solved in some researches by designing a variable step size InCond method. In such techniques, initially, a large step size helps the controller to approach the approximate MPP region and then the accurate MPP will be tracked by a smaller step size. This method increases the accuracy of the controller and avoids oscillation around MPP [44], [45].

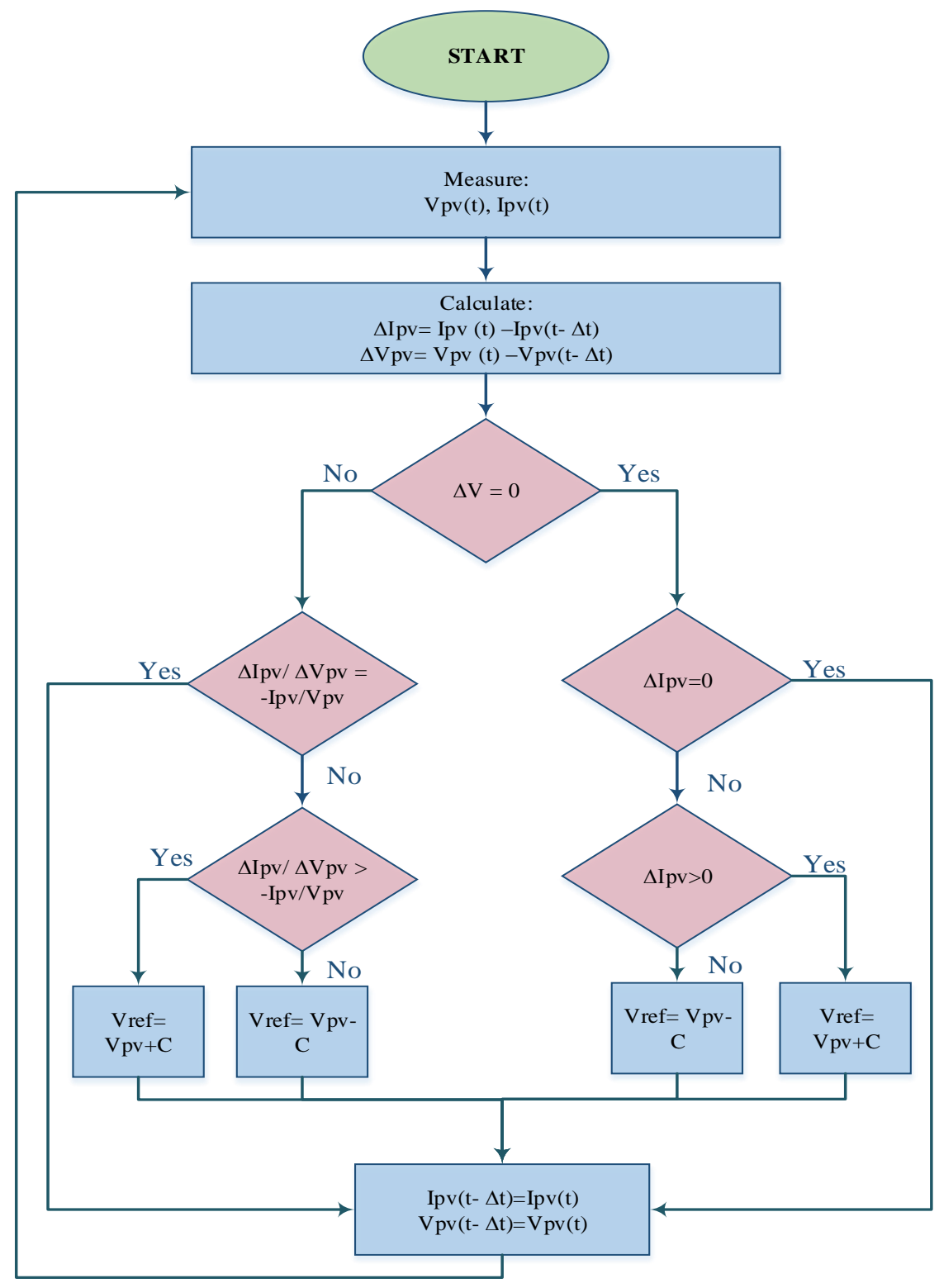

Fig. 5. Flowchart of InCond algorithm.

In contrast to the P\&O method, the most remarkable advantage of the InCond method is its fast and dynamic response under sudden and rapid environmental changes. However, its control circuitry is more complex compared to P\&O technique. In addition, the normal InCond is only able to track the MPP under uniform insolation levels. Under PS condition, the derivation of both local and global MPPs equals to zero, therefore, there is a high possibility for InCond -based MPP tracker to be trapped in a local MPP [46]. Different researches tried to improve the performance of conventional InCond under PS conditions. In [47] a two stage InCond method has been proposed to track global MPP from the output of a partially shaded PV system. In the first step, the neighbouring region of the Global MPP is found and in the second step the 
normal InCond is employed to define the accurate value of Global MPP. The method shows satisfactory results under certain PS conditions, however, it is not reliable to track global MPP under intensive PS conditions.

In another study, the author attempts to find the actual MPP of a grid connected PV system, under PS conditions, by using a linear function [13]. In this study, the proposed algorithm detects the occurrence of the PS when some predefined conditions are satisfied. Once these conditions are met, the linear function is used to move the operating voltage towards the Global MPP region. Then, a normal InCond is used to track the global MPP in that region. The method is successfully verified under some partially shading condition.

In one of the recent studies, Tay Soon in [48] introduced a modified InCond algorithm based on a multifaceted duty cycle control method that effectively utilizes the periodic P-V characteristics of partially shaded conditions. The method is tested under different PS conditions, presented in [9], and verified its functionality with both simulation and experimental verifications. However, the applied modification increases the complexity and computational cost of the normal InCond.

\section{Discussion}

Selection of an appropriate MPPT technique depends on system requirement, system complexity and PV configuration. The MPPT techniques can be classified based on their performance in different PV systems and under different environmental conditions. In this paper, the above mentioned methods have been evaluated based on the following factors: tracking speed, oscillation around MPP, design complexity and ability to track MPP under rapid environmental changes and PS conditions. The summary of these is shown in Table 2.

Table 2. Comparison of Different Conventional Partial Shading Methods

\begin{tabular}{|c|c|c|c|c|c|}
\hline Methods & & Complexity & Oscillation & $\begin{array}{l}\text { Tracking } \\
\text { Speed }\end{array}$ & $\begin{array}{l}\text { Functionality under PS and rapid } \\
\text { Changes }\end{array}$ \\
\hline \multirow{4}{*}{$\mathrm{P} \& 0$} & Normal [19]-[22] & Low & High & High & Unable \\
\hline & Modified in [27] & Average & High & Average & $\begin{array}{l}\text { Able to track under rapid changes, } \\
\text { but not under PS condition }\end{array}$ \\
\hline & $\begin{array}{l}\text { Modified in [24], } \\
{[28]}\end{array}$ & Average & Reduced & Increased & $\begin{array}{l}\text { Just able to track MPP under rapid } \\
\text { changes }\end{array}$ \\
\hline & Modified in [29] & High & Low & High & $\begin{array}{l}\text { Able to track MPP under both } \\
\text { conditions }\end{array}$ \\
\hline \multirow{3}{*}{$\mathrm{HC}$} & $\begin{array}{l}\text { Normal [30]-[32], } \\
{[34],[35]}\end{array}$ & Very low & Average & High & $\begin{array}{l}\text { Unable to track MPP in both } \\
\text { conditions }\end{array}$ \\
\hline & Modified in [16] & Low & Average & Very fast & $\begin{array}{l}\text { Able to track MPP under rapid } \\
\text { change, but not PS }\end{array}$ \\
\hline & Modified in [33] & High & Average & Slow & $\begin{array}{l}\text { Able to track MPP under both rapid } \\
\text { change and PS }\end{array}$ \\
\hline \multirow{4}{*}{ InCond } & $\begin{array}{l}\text { Normal in [11], } \\
{[43]}\end{array}$ & Average & High & Very Fast & $\begin{array}{l}\text { Able to track MPP under rapid } \\
\text { change }\end{array}$ \\
\hline & $\begin{array}{l}\text { Modified in [44]- } \\
{[45]}\end{array}$ & Average & Ave & Fast & $\begin{array}{l}\text { Able to track MPP under rapid } \\
\text { change }\end{array}$ \\
\hline & $\begin{array}{l}\text { Modified in [13], } \\
{[47]}\end{array}$ & High & Low & Average & $\begin{array}{l}\text { Able to track MPP under rapid } \\
\text { change and some PS conditions }\end{array}$ \\
\hline & Modified in [48] & High & Low & Average low & $\begin{array}{l}\text { Able to track MPP under both } \\
\text { conditions }\end{array}$ \\
\hline
\end{tabular}


According to the comparison criteria, it is clear that any modification in the procedure of conventional methods, for improving their detrimental features, can spoil the positive aspects of these methods. For instance, the low design complexity and high tracking speed are the common advantages in the normal form of all conventional methods. However, when a modification is applied to enable them for operating under PS conditions, the extra calculations are needed in order to scan the majority of the search space and distinguish the global MPP from the local ones. Obviously, these extra calculations increase the reliability, accuracy and robustness of the system under any environmental conditions. Nevertheless, they significantly reduce the tracking speed and simplicity of the system.

\section{Conclusion and Future Works}

In regards to the low output rate of photovoltaic systems, extracting the maximum energy from the output terminal is an essential factor in an economic PV system. To achieve this, a capable MPPT method is required in order to provide an appropriate duty cycle signal for the connected DC/DC converter. Different techniques have been employed in the literature and tested in different system configurations and under various environmental conditions. Among these techniques, P\&O, InCond and HC techniques are the most common conventional ones. However, these methods, are not capable of tracking MPP under PS conditions. To solve this, different approaches have been introduced in the literature that can be classified into three main groups. The first group is the modified form of conventional methods, in which an extra calculations or control loops are added in the basic procedure of the algorithm. The second group is the application of artificial intelligent methods such as particle swarm optimization, Fuzzy logic and artificial neural network, which are mostly based on the meta-heuristic approach and the third group is the combination of these two groups, which utilize the advantages of both groups.

In this paper, we concentrated on detailed procedures of conventional MPPT techniques along with their developments towards overcoming their significant drawbacks. Capability of tracking MPP under rapid changes and PS conditions, design complexity, oscillation around MPP and tracking speed are the key factors for evaluating the studied methods. The final comparison proved that, any modification in the basic structure, in order to improve one aspect, might spoil the advantages in another aspect. For instance, almost all modified versions of conventional methods will lose their simplicity and fast convergence characteristics after applying modifications in their basic form. Therefore, a comprehensive knowledge about the nature of the system and its requirements must be considered by the designer in order to select an appropriate MPPT technique.

This study is part of a project which is aimed for providing a comprehensive literature review about all established MPPT methods for all environmental conditions and system requirements. However, according to the large number of proposed methods in the literature, this paper has been concentrated to cover the most common conventional methods and their evolution throughout the recent years. In the next study we present the comprehensive analysis of new approaches, such as artificial and hybrid based methods.

\section{References}

[1] Green, M. A. (1990). Photovoltaics: coming of age. Proceedings of the Twenty First IEEE Photovoltaic Specialists Conference, vol. 1. (pp. 1-8).

[2] Mekhilef, S., Saidur, R., \& Safari, A. (2011). A review on solar energy use in industries. Renewable and Sustainable Energy Reviews, 15, 1777-1790.

[3] Paraskevadaki, E. V., \& Papathanassiou, S. A. (2011). Evaluation of MPP voltage and power of mc-Si PV modules in partial shading conditions. IEEE Transactions on Energy Conversion, 26, 923-932.

[4] Abdelsalam, A. K., Massoud, A. M., Ahmed, S., \& Enjeti, P. (2011). High-performance adaptive perturb 
and observe MPPT technique for photovoltaic-based microgrids. IEEE Transactions on Power Electronics, 26, 1010-1021.

[5] Carannante, G., Fraddanno, C., Pagano, M., \& Piegari, L. (2009). Experimental performance of MPPT algorithm for photovoltaic sources subject to inhomogeneous insolation. IEEE Transactions on Industrial Electronics, 56, 4374-4380.

[6] Fangrui, L., Yong, K., Yu, Z., \& Shanxu, D. (2008). Comparison of P\&\#x00026;0 and hill climbing MPPT methods for grid-connected PV converter. Proceedings of 3rd IEEE Conference on Industrial Electronics and Applications (pp. 804-807).

[7] Guan-Chyun, H., Hung, I. H., Cheng-Yuan, T., \& Chi-Hao, W. (2013). Photovoltaic power-increment-aided incremental-conductance MPPT with two-phased tracking. IEEE Transactions on Power Electronics, 28, 2895-2911.

[8] Hohm, D., \& Ropp, M. (2003). Comparative study of maximum power point tracking algorithms. Progress in Photovoltaics: Research and Applications, 11, 47-62.

[9] Patel, H., \& Agarwal, V. (2008). Maximum power point tracking scheme for PV systems operating under partially shaded conditions. IEEE Transactions on Industrial Electronics, 55, 1689-1698.

[10] Phimmasone, V., Kondo, Y., Kamejima, T., \& Miyatake, M. (2010). Evaluation of extracted energy from PV with PSO-based MPPT against various types of solar irradiation changes. Proceedings of 2010 International Conference on Electrical Machines and Systems (pp. 487-492).

[11] Safari, A. \& Mekhilef, S. (2011). Simulation and hardware implementation of incremental conductance MPPT with direct control method using Cuk converter. IEEE Transactions on Industrial Electronics, 58, 1154-1161.

[12] Silvestre, S., Boronat, A., \& Chouder, A. (2009). Study of bypass diodes configuration on PV modules. Applied Energy, 86, 1632-1640.

[13] Young-Hyok, J., Doo-Yong, J., Jun-Gu, K., Jae-Hyung, K., Tae-Won, L., \& Chung-Yuen, W. (2011). A real maximum power point tracking method for mismatching compensation in $\mathrm{PV}$ array under partially shaded conditions. IEEE Transactions on Power Electronics, 26, 1001-1009.

[14] Jewell, W. T., \& Unruh, T. D. (1990). Limits on cloud-induced fluctuation in photovoltaic generation. IEEE Transactions on Energy Conversion, 5, 8-14.

[15] Sera, D., Kerekes, T., Teodorescu, R., \& Blaabjerg, F. (2006). Improved MPPT algorithms for rapidly changing environmental conditions. Proceedings of 12th International Power Electronics and Motion Control Conference (pp. 1614-1619).

[16] Weidong, X., \& Dunford, W. G. (2004). A modified adaptive hill climbing MPPT method for photovoltaic power systems. Proceedings of IEEE 35th Annual Power Electronics Specialists Conference, vol. 3. (pp. 1957-1963).

[17] Mahmodian, M., Rahmani, R., Taslimi, E., \& Mekhilef, S. (2012). Step by step analyzing, modeling and simulation of single and double array PV system in different environmental variability. Proceedings of International Conference on Future Environment and Energy (pp. 37-42).

[18] Seyedmahmoudian, M., Mekhilef, S., Rahmani, R., Yusof, R., \& Renani, E. T. (2013). Analytical modeling of partially shaded photovoltaic systems. Energies, 6, 128-144.

[19] Hua, C., Lin, J., \& Shen, C. (1998). Implementation of a DSP-controlled photovoltaic system with peak power tracking. IEEE Transactions on Industrial Electronics, 45, 99-107.

[20] Al-Atrash, H., Batarseh, I., \& Rustom, K., Statistical modeling of DSP-based hill-climbing MPPT algorithms in noisy environments. Proceedings of Twentieth Annual IEEE Applied Power Electronics Conference and Exposition (pp. 1773-1777).

[21] Lim, Y. H., \& Hamill, D. (2000). Simple maximum power point tracker for photovoltaic arrays. 
Electronics Letters, 36, 997-999.

[22] Salas, V., Olías, E., Barrado, A., \& Lázaro, A. (2006). Review of the maximum power point tracking algorithms for stand-alone photovoltaic systems. Solar Energy Materials and Solar Cells, 90, 1555-1578.

[23] Hussein, K. H., Muta, I., Hoshino, T., \& Osakada, M. (1995). Maximum photovoltaic power tracking: an algorithm for rapidly changing atmospheric conditions. Proceedings of Generation, Transmission and Distribution, vol. 142. (pp. 59-64).

[24] Femia, N., Petrone, G., Spagnuolo, G., \& Vitelli, M. (2005). Optimization of perturb and observe maximum power point tracking method. IEEE Transactions on Power Electronics, 20, 963-973.

[25] Liu, X., \& Lopes, L. A. (2004). An improved perturbation and observation maximum power point tracking algorithm for PV arrays. Proceedings of IEEE 35th Annual Power Electronics Specialists Conference (pp. 2005-2010).

[26] Xiao, W., \& Dunford, W. G. (2004). A modified adaptive hill climbing MPPT method for photovoltaic power systems. Proceedings of IEEE 35th Annual Power Electronics Specialists Conference (pp. 19571963).

[27] Hua, C., \& Lin, J. (2003). An on-line MPPT algorithm for rapidly changing illuminations of solar arrays. Renewable Energy, 28, 1129-1142.

[28] Kadri, R., Gaubert, J.-P., \& Champenois, G. (2011). An improved maximum power point tracking for photovoltaic grid-connected inverter based on voltage-oriented control. IEEE Transactions on Industrial Electronics, 58, 66-75.

[29] Koutroulis, E., \& Blaabjerg, F. (2012). A new technique for tracking the global maximum power point of PV arrays operating under partial-shading conditions. IEEE Journal of Photovoltaics, 2, 184-190.

[30] Abuzed, S. A., Foster, M. P., \& Stone, D. A. (2014). Variable PWM step-size for modified Hill climbing MPPT PV converter. Proceedings of 7th IET International Conference on Power Electronics, Machines and Drives (pp. 1-6).

[31] Ahmed, A., Li, R., \& Bumby, J. (2012). Perturbation parameters design for hill climbing MPPT techniques. Proceedings of IEEE International Symposium on Industrial Electronics (pp. 1819-1824).

[32] Elgendy, M. A., Zahawi, B., \& Atkinson, D. J. (2011). Dynamic behaviour of hill-climbing MPPT algorithms at low perturbation rates. Proceedings of IET Conference on Renewable Power Generation (pp. 1-6).

[33] Ma, L., Sun, Y., Lin, Y., Bai, Z., Tong, L., \& Song, J. (2011). A high performance MPPT control method. Proceedings of International Conference on Materials for Renewable Energy \& Environment (pp. 195199).

[34] Shimizu, T., Hashimoto, O., \& Kimura, G. (2003). A novel high-performance utility-interactive photovoltaic inverter system. IEEE Transactions on Power Electronics, 18, 704-711.

[35] Kumar, R. (2012). Dependence of hill climbing MPPT algorithm on ADC and Digital filter parameters. In Proceedings of IEEE 5th India International Conference on Power Electronics (pp. 1-4).

[36] Wenkai, W., Pongratananukul, N., Weihong, Q., Rustom, K., Kasparis, T., \& Batarseh, I. (2003). DSP-based multiple peak power tracking for expandable power system. Proceedings of IEEE Eighteenth Annual Applied Power Electronics Conference and Exposition, vol. 1, (pp. 525-530).

[37] Faraji, R., Rouholamini, A., Naji, H. R., Fadaeinedjad, R., \& Chavoshian, M. R. (2014). FPGA-based real time incremental conductance maximum power point tracking controller for photovoltaic systems. Power Electronics, 7, 1294-1304.

[38] Hohm, D. P., \& Ropp, M. E. (2000). Comparative study of maximum power point tracking algorithms using an experimental, programmable, maximum power point tracking test bed. Conference Record of the Twenty-Eighth IEEE Photovoltaic Specialists Conference (pp. 1699-1702). 
[39] Kish, G. J., Lee, J. J., \& Lehn, P. W. (2012). Modelling and control of photovoltaic panels utilising the incremental conductance method for maximum power point tracking. Renewable Power Generation, 6 , 259-266.

[40] Yeong-Chan, K., Tsorng-Juu, L., \& Jiann-Fuh, C. (2001). Novel maximum-power-point-tracking controller for photovoltaic energy conversion system. IEEE Transactions on Industrial Electronics, 48, 594-601.

[41] Yu, G. J., Jung, Y. S., Choi, J. Y., Choy, I., Song, J. H., \& Kim, G. S. (2002). A novel two-mode MPPT control algorithm based on comparative study of existing algorithms. Conference Record of the Twenty-Ninth IEEE Photovoltaic Specialists Conference (pp. 1531-1534).

[42] Urayai, C., \& Amaratunga, G. A. (2013). Single-sensor maximum power point tracking algorithms. Renewable Power Generation, 7, 82-88.

[43] Esram, T., \& Chapman, P. L. (June 2007). Comparison of photovoltaic array maximum power point tracking techniques. IEEE Transactions On Energy Conversion, 22, 439-449.

[44] Qiang, M., Mingwei, S., Liying, L., \& Guerrero, J. M. (2011). A novel improved variable step-size incremental-resistance MPPT method for PV systems. IEEE Transactions on Industrial Electronics, 58, 2427-2434.

[45] Ahmed, E. M., \& Shoyama, M. (2011). Stability study of variable step size incremental conductance/impedance MPPT for PV systems. Proceedings of IEEE 8th International Conference on Power Electronics and ECCE Asia (pp. 386-392).

[46] Ishaque, K., \& Salam, Z. (2013). A review of maximum power point tracking techniques of PV system for uniform insolation and partial shading condition. Renewable and Sustainable Energy Reviews, 19, 475488.

[47] Kobayashi, K., Takano, I., \& Sawada, Y. (2006). A study of a two stage maximum power point tracking control of a photovoltaic system under partially shaded insolation conditions. Solar Energy Materials and Solar Cells, 90, 2975-2988.

[48] Kok, S. T., \& Mekhilef, S. (2014). Modified incremental conductance algorithm for photovoltaic system under partial shading conditions and load variation. IEEE Transactions on Industrial Electronics, 61, 5384-5392.

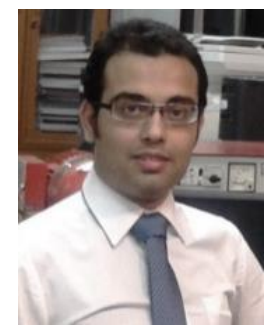

Mohammadmehdi Seyedmahmoudian received his B.Sc. degree in electrical engineering from IAU, Esfahan, Iran, in 2009, and the M.Eng. degree in Industrial Control and Electronic (Hons) from the University of Malaya, Kuala Lumpur, Malaysia. From 2012 to 2013, He was a research assistant in the Department of Electrical Engineering, University Malaya, Kuala Lumpur, Malaysia.

$\mathrm{He}$ is currently pursuing the Ph.D. degree in electrical engineering at School of Engineering, Faculty of Science, Engineering and Built Environment, Vitoria, Australia. His research intrests includes photovoltaic systems, micro grid systems and the artificial intelligence applications in control and optimization.

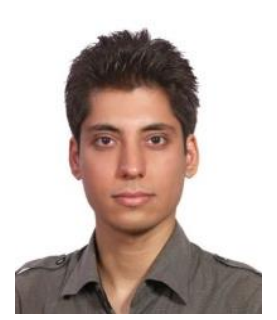

Arash Mohammadi received the B.Sc. degree in electrical engineering from Isfahan University of Technology (IUT) in 2008 and M.Eng degree in electrical energy and power system from University of Malaya (UM) in 2012. He is currently doing research on renewable energy, fuzzy logic, MATLAB modeling, and artificial intelligence. 


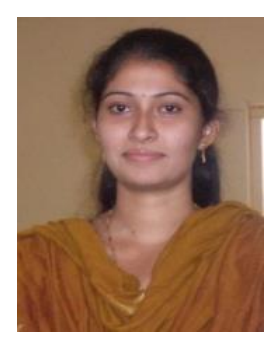

Swarna Kumary is pursuing Ph.D degree from Deakin University, Australia. She received M.Tech degree in VLSI design from St. Mary's College of Engg. and Technology, Hyderabad, in 2012, received B.Tech degree in electronics and communication engineering from HITECH College of Engineering, affiliated to JNTU Hyderabad in 2008.

Her research interests include renewable and sustainabl energies, image processing and coding techniques, MOS design, cryptanalysis, wireless mobile communication, digital communication and digital signal.

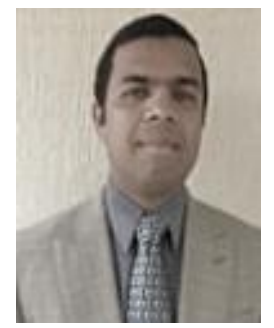

Amanullah Than Oo received the B.Eng. (Hons) and the M.Eng degrees in engineering from IIUM and the Melbourne University respectively and a Ph.D. degree in electrical engineering from Victoria University, Melbourne, Australia. He is an associate professor in electrical engineering and has a strong research interest in renewable energy, smart grid and power systems. He has been invited to deliver key note addresses and presentations in a number of national and international workshops and conferences. He has more than 160 peer reviewed conferences and journals publications. Aman has supervised more than $25 \mathrm{PhD}$ students in power systems, renewable energy systems and its enabling technologies.

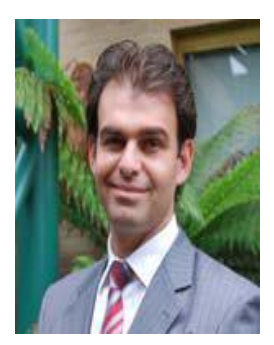

Alex Stojcevski is the head of Dept. of Electrical \& Electronics Engineering and also is the deputy head of School of Engineering at Deakin University. Alex holds a doctor of Philosophy degree, masters by research degree in electrical and electronics engineering, and a bachelor degree in electrical engineering. He also holds a masters degree in education and a masters degree in project based learning (PBL) in engineering and science from Aalborg University in Denmark. He has held numerous senior positions across four universities and two continents. Professor Stojcevski's research interests are in renewable energy and micro grid design. He has published more than 150 book chapters, journals, and conference articles and has given a number of internationally invited speaker presentations. 